\title{
OS (D)ANOS DA COLONIZAÇÃO, AS IDENTIDADES PÓS-COLONIAIS E A BUSCA DA GUINENDADE EM A ÚLTIMA TRAGÉDIA DE ABDULAI SILA
}

\author{
The damage/years of colonization, post-colonial identities and the search for \\ guinendade in the Last Tragedy of Abdulai Sila
}

\section{Jonh Jefferson do Nascimento Alves}

http://orcid.org/0000-0001-8411-4571

Universidade Federal de Alagoas, Programa de Pós-Graduação em Linguística e Literatura, Maceió, AL, Brasil. 57072-900-ppgll@fale.ufal.br

Resumo: O presente estudo versa sobre a narrativa da nação como representação coletiva tematizando a violência e o trauma contra o povo guineense. $\mathrm{O}$ texto permite o encontro entre discursos coloniais, preconceitos e efeitos traumáticos sobre a identidade africana, indagando o quanto os projetos e sonhos nacionalistas na Guiné-Bissau foram realmente alcançados e como o passado contribuiu para a instabilidade política e os falhanços econômicos vivenciados na contemporaneidade. Neste sentido, tomamos por corpus de análise a obra ficcional $A$ Última Tragédia de Abdulai Sila (2002), voz de uma sociedade complexa e atual, cujos textos abordam especificamente a tentativa de constituir uma reflexão sobre a identidade nacional e a história dos guineenses em contextos pós-coloniais. A produção artística - aqui particularmente a literatura - surge como parte do processo de consolidação de identidades, por meio de seu caráter de representação. A Última Tragédia de Abdulai Sila (2002) parece buscar num passado ainda vivo e presente, as respostas que justifiquem a origem das adversidades comuns do país na atualidade.

Palavras-chave: Trauma colonial. Nacionalismo. Identidade. Pós-colonialismo.

Abstract: The present study deals with the nation's narrative as a collective representation with the theme of violence and trauma against the Guinean people. The text allows the encounter between colonial discourses, prejudices and traumatic effects on African identity, asking how far the nationalist projects and dreams in Guinea-Bissau were really achieved and how the past contributed to the political instability and the economic failures experienced in contemporary times. In this sense, we take as a corpus of analysis the fictional work The Last Tragedy by Abdulai Sila (2002), voice of a complex and current society, whose texts specifically address the attempt to constitute a reflection on the national identity and the history of guineans in

Esta obra está licenciada sob uma Creative Commons - Atribuição 4.0 
contexts post-colonial. Artistic production - particularly literature here - emerges as part of the process of consolidating identities, through its character of representation. Abdulai Sila's Last Tragedy (2002) seems to seek answers that justify the origin of the country's common adversities today, in a still alive and present past.

Keywords: Colonial trauma. Nationalism. Identity. Post-colonialism.

Sobre as Literaturas Africanas de Língua Portuguesa, é interessante comentar que estas constituem um exemplo fortemente relevante sobre a questão da alteridade enquanto objeto de reflexão, poder de marginalização dos indivíduos e de culturas inteiras, exercido pela elite dominante. Neste sentido, tais literaturas se convertem em temáticas proficuamente pertinentes para a análise, em uma perspectiva crítica pós-colonial, como instrumento para a verificação de como a escrita literária está a serviço da constituição nacional, de identidades, de denúncias e resistências das culturas que outrora foram mantidas nas penumbras da história e das civilizações ocidentais, como fonte de dominação.

No caso da Guiné-Bissau, a questão da barbárie e da pilhagem dos bens culturais passa pela questão central da língua nacional, ou seja, o conflito entre a adoção da língua portuguesa como língua de expressão cultural e política ao mesmo tempo em que foi a língua da dominação exercida pelo colonizador, em contraponto com o mosaico cultural composto pelas línguas nativas. Neste caso, língua e literatura são usadas pelos sujeitos colonizados para desmantelar a dependência cultural, em um amplo e profundo resgate das origens culturais, arrasadas e silenciadas durante o processo de colonização, reconstruindo a própria identidade, cultura e história, por ela apagadas. Para Walter Benjamin (1985),

[...] Não há documento da cultura que não seja ao mesmo tempo um documento de barbárie. E assim como os próprios bens culturais não estão livres de barbárie, também não o está o processo de transmissão com que eles passam de uns a outros. Por isso, o materialismo histórico se afasta o máximo possível da tradição. Ele considera como uma tarefa sua pentear a história a contrapelo. (BENJAMIN, 1985, p. 156-157).

A história dos eventos literários como reflexo de um passado, para o historiador estadunidense Hayden White (1994), só se torna familiar quando caem por terra os pontos de estranhamento que impede a sua interpretação através da leitura narrativa. Assim, o leitor, ao acompanhar tais relatos, vê a estranheza dissolver-se pela lógica do entendimento e, portanto, passa a compreender a concatenação de acontecimentos subordinados aos relatos históricos, sem superestimá-los na ordem cronológica. Desta forma, à medida que o leitor os consome, tais acontecimentos tornam-se íntimos através do enredo permitido pela literatura ou pela historiografia.

Passeando pela psicoterapia, Hayden White (1994) observa que o conjunto de eventos do passado, de memória, é a miúde, a causa do sofrimento, o qual se manifesta através de uma síndrome onde tais acontecimentos tornam-se estranhos e deixam de ser, portanto, familiares, enfatizados a todo o momento pela memória e pela dor que causam nos sujeitos. Tais eventos assumem ares de estranheza, mistério, medo que o paciente não consegue aceitar e tampouco 
excretar de suas lembranças. Contudo, tais acontecimentos encontram-se carregados de um sentido extremamente intenso e doloroso, que se soma à consciência, confundindo-se com o real ou o imaginário, estes "continuam a moldar tanto as suas percepções como as suas respostas ao mundo por muito tempo depois que deveriam ter-se tornando "história passada"' (WHITE, 1994, p. 103).

O caminho, segundo White (1994) é a condução do paciente, através da psicoterapia, a um mergulho na história de sua vida com o objetivo de mudar o sentido, (res)significando os eventos para a economia de acontecimentos que compõem a experiência narrativa. A terapia através do ato de narrar os acontecimentos, é "um exercício no processo de refamiliarizar os acontecimentos que deixaram de ser familiares, que se alienaram da história de vida do paciente em virtude de sua sobredeterminação com forças causais" (WHITE, 1994, p. 104). O resultado é que os acontecimentos na teia narrativa perdem o caráter traumático que possuíam, removidos da estrutura de enredo onde ocupam um lugar predominante, para depois serem ressignificados, refamiliarizados e, assim, inseridos em outra estrutura que têm uma função subordinada, banal, comparável aos demais elementos partilhados com a experiência da coletividade humana.

Deste modo, a literatura pós-colonial dedica atenção para questões de como elementos de violência, trauma e dor ocorrem na prática de rememoração do passado colonial e pós-colonial de sujeitos que viveram ou não sob a herança do estigma do subjugo. Com efeito, a GuinéBissau foi e ainda é cenário de duras penas perpetradas contra os homens, nativos, negros. Contudo, tais experiências, decerto, atingiram a população de forma diversa, em diferentes graus de internalização e de expressão do trauma através de narrativas ficcionais. Deste modo, enquanto alguns escritores são representantes legítimos das vítimas da violência e do trauma, uma vez que também foram ou são vítimas diretas, outros não participaram dos atos de violência diretamente, embora sejam delas herdeiros através de gerações.

Nomes como Abdulai Sila sentem-se tocados profundamente pela questão da dor e do trauma infligido ao seu povo através de um processo de identificação que somente a cultura e a alteridade permitem. Nele percebemos que a produção cultural pós-colonial, em especial a literatura, com suas narrativas ficcionais, constitui um campo complexo e heterogêneo de estudos e pesquisas, de modo que é possível encontrar uma miríade de expressões literárias e estratégias sobre a violência coletiva, a dor e o trauma. $\mathrm{O}$ debate sobre a literatura do trauma tem como característica uma enorme variedade de abordagens úteis à maturação do debate na esfera da pesquisa acadêmica. Tais narrativas oferecem a possibilidade, portanto, de lidar com um conteúdo autêntico, de expressão genuína da dor e do trauma, constituindo um esforço ficcional de como o passado aconteceu em termos coletivos.

Guiné-Bissau é um Estado africano que sempre, dos territórios em África, apresentou maior resistência ao poder colonial da metrópole portuguesa e um dos primeiros países a se tornar independente. Nos últimos 40 anos, o país viveu sucessivas transformações, fator que tem depreciado fortemente a política nacional e propagado o autoritarismo partidário. A despeito de qualquer condicionamento, o país é um lugar de expressiva solidariedade e de efervescente cultura. Em Moema Parente Augel (1998), observamos que, na "conjuntura dos 
cinco", a produção fíccional silariana se apresenta como uma espécie de "espelho crítico da sociedade" (AUGEL, 1998, p. 19), ajudando a lançar luz sobre o inconsciente coletivo da população. A produção literária contemporânea da Guiné-Bissau reflete, de forma muito especial, os anseios e preocupações da elite intelectual urbana.

Dos textos, selecionamos $A$ Última Tragédia (2002) por representar fortemente aspectos do trauma políticos e sociais que se revelam como heranças coloniais. É importante comentar que as literaturas em Abdulai Sila se encontram precisamente na fronteira entre história e ficção, configurando a metaficção historiográfica, tornando difícil saber até que ponto a colonização portuguesa guineense, nos romances, está transformada em ficção. Na obra, o autor aborda o lado oculto da guerra colonial, denunciando e apontando, por meio de conflitos, a relação entre dominadores e dominados; apresentando-nos uma urdidura dotada de reflexão sobre os traumas que moldaram a identidade nacional.

A Última Tragédia parece buscar num passado recente as respostas que justifiquem as adversidades comuns na atualidade. Observamos no texto o descortinar da coletividade guineense ilustrada nas personagens: Ndani, uma adolescente nativa que sai de seu povoado (Biombo) para a capital (Bissau) em busca de trabalho e libertação de um carma espiritual; o régulo (Bsum Nanki) líder analfabeto e astuto de uma aldeia (Quinhamel); e um professor cujo nome, o narrado não revela. O narrador apresenta-nos um panorama de como era o convívio entre africanos e europeus, cosmovisões que desembocam em um todo articulado sobre as relações humanas e os papeis sociais dos indivíduos. Nesta perspectiva, observamos que a pluralidade identitária advinda do contato se aglutina formando um todo complexo e excitante no convite da análise.

Ndani era uma jovem que vivia uma espécie de conflito entre dois mundos, o do colonizador e o do colonizado, ela almeja a libertação de seu estigma espiritual, que segundo um Djambaku (feiticeiro/curandeiro) da tabanca/comunidade local afirma ter ela "um mau espírito, a alma de um defunto, que lhe vaticinara consequentemente uma existência turbulenta, uma vida de desgraças, de tragédias até o fim [...]”. (SILA, 2002, p. 27). Ingênua, curiosa e submissa, Ndani é empregada na casa de Maria Deolinda (Dona Linda), uma senhora portuguesa de 50 anos esposa do Senhor Leitão. Lá, Ndani é em princípio agredida e vive a mercê do jugo e das duras ordens da patroa:

Ainda não esquecera a bofetada que lhe dera um dia quando o gato comeu uma posta de peixe... Às vezes chamava nomes feios, palavras que ela não entendia [...] Nos primeiros tempos, quando a patroa lhe controlava a comida, dando-lhe somente o que sobejava da mesa deles... porque ela era criado... (SILA, 2002, p. 32 e 38).

Nesse e em outros fragmentos, nos familiarizamos com a rotina de uma guineense violentada de múltiplas maneiras pelo colonizador. O batismo de Ndani dentro dos moldes europeizantes é um elemento notadamente simbólico de trauma sugerindo uma forte expressão dessa aculturação onde as imposições expressam real efeito de poder de desconstrução e reconstrução: 
—Como é que te chamas?

- $\mathrm{Hmm}$ ?

- O teu nome, caramba!

- Aah, Ndani, senhora. Ndani.

— Como é que é? Dánia? Dánia... mas este é um nome russo, nome comunista. Ave Maria! Vocês arranjam cada uma... com tanto nome bonito português que há por ai, o teu pai escolhe para ti um nome russo! [...] A gente vem pra esse inferno para civilizar-vos e vocês a criarem confusão... nome comunista na minha casa é que não vou tolerar. Nunca! O teu nome vai ser Daniela, ouviste? A partir de hoje, tu és Daniela, Da-ni-e-la. Maria Daniela e mais nada. (SILA, 2002, p. 30).

Como visto, antes de condicionar a cultura do Outro, o colonizador europeu constrói a identidade dele se utilizando de arquétipos fixos e imutáveis (BHABHA, 1998, p. 105). Daniela deixa de ser reconhecida pelo seu nome "nati-cultural" abrindo portas para muitas outras imposições sob o prisma de desculturação. Acostumada ao novo nome, ela chega inclusive a pensar que sempre se chamou Daniela. "Isso porque a perda do nome deve ser vista como a representação da perda da identidade africana em favor da portuguesa, como suplantação da cultura supostamente inferior pela dita superior" (VALANDRO, 2011, p. 53).

A mudança de nome a submete ao convívio com a negação dos valores tradicionais e religiosos uma espécie de "condenação à morte cultural". Para Daniela, esse novo nome faz dela sujeito integrante daquele espaço e/ou daquela cultura. Segundo Jean Chevalier e Alain Cheerbrant (2009),

[...] o nome pessoal é bem mais que um signo de identificação. É uma dimensão do indivíduo. O nome será coisa viva. Encontram-se no nome todas as características do símbolo: 1. Ele é carregado de significação; 2. Escrevendo ou pronunciando o nome de uma pessoa, faz-se com que ela viva ou sobreviva. 3. O conhecimento do nome proporciona poder sobre a pessoa [...]. (CHEVALIER; CHEERBRANT, 2009 p. 641).

Esses pontos revelam e problematizam a presença de elementos opositores na diegese: o eu, configurado pelo africano em Daniela e o outro, o branco colonizador em Dona Linda.

Acerca disso, Frantz Fanon (2008) nos fundamenta na observação das vivências e interações onde, em muitos contextos, o negro começa a fantasiar a vida do branco constatando que seu inconsciente coletivo de africano é "o mesmo do europeu colonizador". (FANON, 2008, p. 188). Para Fanon (2008), tudo nessa construção é manipulado em um cenário global traumático. Como representações coletivas esses opostos refletem uma necessidade da postura subserviente e inferiorizada do negro onde o preconceito e a violência eurocêntrica dão o tom. De fato, esta era uma ferramenta amplamente usada com a única finalidade de impor sua cultura aos povos subjugados. No colonialismo guineense, os conflitos sempre se fizeram presentes, claro que nem sempre de forma pacífica.

Nesta perspectiva, surge então uma categoria de indivíduo: a do nativo que não faz mais parte de um grupo étnico tradicional e também não é um cidadão português pleno. Trata-se então de um cidadão de segunda classe, um cidadão de casta inferior: o negro assimilado. Dessa 
forma, o assimilado, não consegue alcançar o objetivo de se identificar com os colonizadores, pois para eles continua sendo o Outro. Só que agora ensinado, disciplinado, domesticado, mas ainda é um sujeito diferenciado. A complexidade desse processo ainda se torna mais vigente com o fato de a sociedade porfiadosamente priorizar o falocentrismo e sua condição de mulher e assimilada requerer um matrimônio, conjuntura muitas vezes arranjada pelas patroas.

É aí que entra o régulo, chefe de uma aldeia chamada Quinhamel, a quem Daniela seria prometida em casamento - afinal, negros só poderiam casar-se com negros; seu nome nativo é Bsum Nanki, sujeito autóctone que comandava seu povo em uma espécie de parceria com a administração portuguesa. Seu contato com Dona Linda se dava pela aproximação que ele, por conta da administração colonial, mantinha com a igreja a qual Dona Linda era beata e convertera Daniela. Em Moema Parente Augel (2005), o termo régulo, é visto como um diminutivo de rei e os colonizadores o empregavam pejorativamente como "reizinho" para designar o chefe máximo dos agrupamentos étnicos.

Alicerçada no menosprezo, os portugueses sempre contaram com a colaboração de régulos agindo como funcionários do governo na zona rural; a participação de nativos nessa ocupação, por muito tempo, mostrou-se importante, pois sem tais contribuições a colonização não teria êxito. Se por um lado, os portugueses contavam com o auxílio de chefes tribais submissos nas conquistas dos territórios africanos, por outro, a diegese silariana se alicerçava no fato de muitos desses chefes não aceitarem tais imposições, o que em A Última Tragédia é vivificado na resistência e caracterização onde as personagens usam inclusive estratégias dos próprios brancos para demarcar seus territórios.

Tais características podem ser respigadas onde Bsum Nanki, mesmo declarando não gostar de brancos, reconhece a possibilidade de poder aprender com eles, sobretudo em sua capacidade de pensar:

Havia muita coisa que não andava como deve ser e as pessoas deixavam andar. Porquê? Porque não pensavam. A cabeça não era só para pôr chapéu, toda a gente sabe. É para pensar também. Veja só como fazem os brancos. Não é que ele goste dos brancos, longe disso. Mas há que ver uma coisa, não vale a pena dizer que não se vai olhar para o rosto de uma pessoa só porque alguém disse que essa pessoa é feia. Às vezes até é necessário olhar ainda mais que é para saber exactamente o que é que é feio, se tudo é que é feio ou se há algumas coisas que não são feias. (SILA, 2002, p. 64).

Nesta perspectiva mítica de verticalidade, fruto de uma consciência crítica marcada por um instinto profundo de liberdade coletiva e por uma coerência inabalável é que Abdulai Sila (2002) narra a postura do régulo em suas vivencias com o colonizador. Este é concebido com expressiva e necessária dificuldade de confiar nos brancos, pois para ele, a capacidade de articulação de pensamentos próprios desses indivíduos proporcionava a eles uma postura dominadora sobre os negros acentuando uma coabitação ilegítima e astuta:

O branco está a dominar o preto é só porque não há ninguém a pensar. Ninguém diz isto está bom, aquilo está mal e depois procura pensar porquê. Tudo que o branco faz é porquê está bom. O branco é que estava a pensar no 
lugar do preto. Mas branco é homem como qualquer outro homem! (SILA, 2002, p. 76).

Sobre a postura do régulo, observamos um comportamento que Homi Bhabha (1998) convencionou chamar civilidade dissimulada ou cortesia dissimulada, mecanismo que se refere ao uso de uma "falsa cortesia", de uma suposta "aceitação" por parte do colonizado às imposições típicas da presença europeia, o que na realidade constitui-se uma forma de o sujeito não entrar em conflito direto com o europeu e continuar cultivando seus costumes e ainda fracionar a autoridade do colonizador. Nesse tipo de resistência, o sujeito faz uso de elementos da cultura europeia em favor de si próprio, transformando esses elementos, utilizando-os de forma subvertida e acima de tudo questionando sua real condição em relação ao Outro.

Na obra Os condenados da terra, de Frantz Fanon (2010), observamos uma predisposição do colonizado a uma encenação, um papel que estimula o negro a superar o medo imposto pela violência do colonizador, tomando consciência de sua força revolucionária combatendo ou tentando combater as mazelas desencadeadas pelo capitalismo colonial, mais uma vez uma espécie de instabilidade emocional - trauma - advinda das sujeições oriundas do contato com o europeu:

[...] o determinismo é de origem psíquica. Essa patologia é considerada uma maneira de que se vale o organismo para responder, isto é, adaptar-se ao conflito que se lhe depara, sendo a perturbação ao mesmo tempo sintoma e cura. Mais precisamente, todos são unânimes em afirmar que o organismo supera o conflito por vias nocivas, mas de resto econômicas. É o mal menor que o organismo escolhe para evitar a catástrofe. (FANON, 2010, p. 250).

O que ainda parecia segredo sobre os planos do régulo é que ele, enquanto chefe tribal pretendia levar o conhecimento a todos os seus e por meio do valor do pensamento fomentar a luta contra a opressão colonial que para ele não carecia de força; a inteligência e o conhecimento eram os elementos mais necessários. - Como fazê-lo, sendo ele analfabeto? - Ainda gozando de "prestígio", Bsum Nanki sugere a contratação de um professor para lecionar em uma escola da região que fora inaugurada recentemente, este por sua civilidade dissimulada conta com forte influência de Dona Linda e do Padre.

Bsum Nanki solicita ao novo Professor - negro - que o ajude a escrever um testamento onde deixaria conselhos, princípios e ensinamentos para toda família e outros que viessem a ocupar o seu posto. Por não saber escrever contaria com o letramento deste, para redigir o que ditaria:

Régulo deve ser aquele que sabe pensar melhor, aquele que consegue ir até à essência das coisas. Régulo só pode ser quem tem as mãos limpas, sem rabo de palha... E depois ele tem que ter uma visão mais aberta. Quando há um problema, tem que ser capaz de distinguir a causa da consequência. (SILA, 2002, p. 115).

Infelizmente o régulo não conseguiu completar o seu testamento. Após dois anos veio a óbito: “... Ele morreu sem ter adoecido um único dia, o grande régulo de Quinhamel. Teve uma 
morte lenta e calma, como o vento que soprava nessa manhã...” (SILA, 2002, p. 117). O povo comentava que desde que se casara com Daniela que era portadora de tragédias, ele havia mudado, não era mais o mesmo, vivia entristecido e a velhice se apoderara dele rapidamente. Restando apenas suas memórias e o seu legado, a representação da resistência em seu país. A ideia de registrar por escrito o que poderia deixar de herança para todos os moradores de sua terra era a materialização de um plano que possibilitaria a libertação do negro e do seu território das explorações do branco:

Isso é para toda a gente desta terra, mas mesmo toda gente... [...] É para os meus parentes e para os parentes dos outros também. É para toda a gente que quer. É por isso que quero isso escrito [...] um plano de como tirar os brancos a mandar nesta terra. Não! Não é matar ninguém. Não é matar nem expulsar ninguém. É só pôr os brancos no seu lugar. [...] Essa coisa de uma pessoa ir mandar na terra de outras pessoas não me agrada, não estou de acordo. (SILA, 2002, p. 102 e 107).

Ao testamentar parte de seus planos, o régulo publiciza uma atitude que vai de encontro ao discurso colonial, para o qual o negro era tido como sem capacidades intelectuais. O narrado traz na personagem o ponto de vista do nativo na perspectiva da inversão. Uma narração da nação onde a ambivalência da interação entre as culturas mostra personagens se apropriando das armas do opressor - a língua e a cultura - na luta pela libertação, bem como pela (re)afirmação de sua identidade nacional.

Sobre a personagem do professor, este evolui da necessidade europeizante de referenciar a conduta, os costumes e a língua portuguesa entre os nativos. Ele, de acordo com o texto, foi intelectualizado dentro dos moldes evangelísticos, sendo um dos primeiros frutos da missão dos colonizadores para com os africanos na Guiné-Bissau. Em princípio mostra-se respeitoso com os costumes, pelo menos enquanto não contraditavam com as suas convicções, uma postura ligeiramente ambivalente. Segundo Homi Bhabha (1990), a ambivalência ou o "passear em dois mundos", é importante na construção de uma identidade, visto que a ideia de nação nesse contexto vem de uma elite não do povo, ou como afirma Bhabha (1990, p. 01), “(n)ações, como narrativas, perdem suas origens nos mitos do tempo e só realizam plenamente seus horizontes no olho das mentes".

O que acontece de fato e novamente é a utilização de ferramentas de combate velado. Os ensinamentos do professor se traduzem mais como uma resistência à aculturação e a valorização da cor que a transmissão das concepções do branco colonizador. A personagem em seu espaço educacional busca abolir pensamentos do tipo: "Um professor preto? Por que não um branco, como nas outras terras? O branco sabe mais, pode ensinar mais. Agora o que é que um professor preto sabe?" (SILA, 2002, p. 95). Sila (2002) deixa claro no narrado que a valoração do nativo e da cultura é uma atividade constante. Estas formas sutis e mais difundidas de resistência são as mais importantes porque são as mais difíceis para os poderes imperiais combaterem.

Sobre "guinendade" é importante explicar, segundo Moema Parente Augel (2009), é a capacidade, assim como em muitos Estados modernos, de comporem e fixarem sua nacionalidade, estes, por exemplo, possuem uma longa história de formação nacional, com 
símbolos, datas e heróis para criarem e estimularem o sentimento de pertença do cidadão a essa unidade abstrata e emocional que é a Nação. A consciência da diversidade étnica obriga, portanto, os países africanos a reinventarem-se como complexos culturais pluriétnicos, e, no caso da Guiné-Bissau, em busca de uma identidade comum e solidária, dentro da diversidade, inventa-se o conceito de guinendade, assim como em outros países de língua portuguesa os correspondentes. Para a pesquisadora, a Guiné-Bissau,

Carece de uma estratégia a ser perseguida com a finalidade de esboçar, divulgar e alimentar o Projeto Guiné-Bissau. Fazem parte da salvaguarda da memória nacional e coletiva, igualmente, os monumentos e os museus, os arquivos e as bibliotecas, assim como os festejos de caráter comunitário. A intenção didatizante e política, no sentido lato do termo, é preservar a memória coletiva $[\ldots .$.$] e a construção da guinendade comemorando efemérides,$ celebrando guerras passadas com o culto aos heróis e a lembrança dos mortos, animando o grupo social através de paradas cívicas e hinos patrióticos. (AUGEL, 2009, p. 146).

O reflexo sobre a guinendade é um dos pontos ressaltados com muita consciência pelo autor na personagem do professor, explorando o sentimento e o orgulho nacional por meio da educação e da subversão do trauma. O resultado disso é um maior entusiasmo na própria personagem que não hesita em suplantar a linha do pensamento segregatório pregado pela igreja, divulgando cada vez mais forte e consciente a importância dos valores tradicionais:

À tarde, as sessões de catequese foram substituídas por desporto. Corriam e jogavam futebol todos os dias. O professor falava cada vez menos das coisas do céu. Os alunos pensaram que era uma situação passageira, sol de pouca dura, mas enganaram-se. As coisas da terra passaram a ter prioridade. Queria saber quando é que seria o próximo fanado; quem era o melhor tocador de tambor; quando é que seria o toca-tchur de fulano de tal e tal. (SILA, 2002, p. 125 , grifo no original).

Nos meses que se passaram após a chegada do professor e das visitas à casa do régulo para ajudá-lo no suposto testamento, este passa a perceber que mesmo com toda limitação de letramento, as intenções de Bsum Nanki se encerram na nobreza de salvaguardar a cultura e as tradições do seu povo por meio de conselhos e relatos de experiência. Com isso o professor acaba por perceber que ele não podia simplesmente renegar todos os valores ou as tradições de sua comunidade e reconhece que o mais sensato é fazer uso de seu conhecimento para questionar o lugar do negro na sociedade colonial.

Depois de muito frequentar a casa do régulo, o professor descobre nutrir uma afeição por Daniela e percebe haver reciprocidade na paixão, porém, o respeito que tinha para com Bsum Nanki o afastava dessa inspiração. Daniela que nunca tivera um verdadeiro amor agora cogitava externar seus reais sentimentos:

Diferente dos outros dias em que acordava, olhava à volta e via tudo incolor, tudo monótono, tudo sem vida. Pela primeira vez, ouviu o canto dos passarinhos no quintal, viu os raios do sol que penetravam alegremente no seu quarto e enchiam de brilho tudo quanto nele havia. Os objetos brilhavam aos 
seus olhos de uma forma estranha, cheios de vida e de cor. Sentia o movimento suave do ar que entrava pela janela semi-aberta, o aroma das flores do mangueiro no quintal, que chegavam até ela, despertando sensações desconhecidas. Levantou-se e olhou à volta. Um sorriso apareceu nos seus lábios. Ele viria à tarde... (SILA, 2002, p. 124).

Sem conseguirem mais esconder o sentimento um pelo outro, Daniela, apaixonada, esperava todos os dias pela vinda do professor e este também vivenciava essa transformação: No início, não passava de uma simples tentação, tentação ou aventura, pois não sabiam explicar direito. O que conseguem explicar é que desde a primeira vez que se viram sentiram uma forte atração, algo que os puxava para perto um do outro. O Professor queria continuar a vê-la, só vê-la. O amor em Daniela é visto como uma forma de libertação; libertação dos medos, traumas e receios pelo qual passara por toda a vida. Ambos apaixonados deixaram de se importar como aquele amor proibido era visto pela sociedade de Quinhamel.

O régulo, antes de morrer, já sabia da relação entre os dois e até chegara a dizer ao professor que aproveitasse. Após a morte Bsum Nanki, mudaram-se de cidade. Já tinham dois filhos e decidiram ir para Catió ao sul da Guiné-Bissau, onde poderiam viver suas vidas sem que ninguém os reconhecesse e os julgasse. Lá, o professor voltou a lecionar e a participar dos jogos de futebol que eram tradição na cidade. Em um jogo de comemoração a chegada do novo Administrador, o professor assustou-se quando percebeu que este era o mesmo administrador que agredira seu pai no passado. Quis desistir, mas não conseguiu. Durante o segundo tempo, o filho do administrador entrou no jogo, no time adversário, e julgando-se injustiçado desafiou o professor, fazendo-o tropeçar várias vezes até machucar-se:

Ao receber a bola de um companheiro, ofereceu-a propositalmente ao rapaz, que logo levantou o pé para pontapeá-lo com força para frente. Deu-lhe uma staka tão bem dada que caiu de imediato e começou a gritar que os cachorros dos pretos lhe tinham partido o pé. (SILA, 2002, p. 159).

Nesse momento o Administrador foi de encontro ao professor e o deu uma bofetada no rosto. O professor, em uma mistura de fúria e desejo de vingança, respondeu a agressão, em sua memória surgira como um relâmpago uma cena idêntica, uma projeção do trauma vivenciado há muitos anos na sua tabanca natal. Um comerciante branco tinha acabado de esbofetear o seu pai. Avistou a mão branca a aproximar-se outra vez do seu rosto. Sentiu a cólera crescer dentro de si. Não sabia bem ser era uma onda de fúria ou um desejo de vingança. Reagiu com extrema rapidez. "Desviou todo o tronco para trás e viu a mão passar perto do seu nariz, assobiando. No instante seguinte era o seu punho a embater nas bochechas do branco..." (SILA, 2002, p. 159).

Todos ficaram surpresos com a reação do professor e aguardavam os resultados dessa adversidade. Esperavam que o professor fosse preso, torturado e até morto pelos cipaios (soldados que serviam ao exército da corte). Porém, uma semana depois o Administrador foi encontrado morto no banheiro de sua casa, vítima de um infarto, segundo o médico legista que o examinara. Mas, como todos esperavam pela vingança do Administrador, o investigador de polícia decidiu incriminá-lo pela morte combinando inclusive com um guarda e com a 
cozinheira da casa que dissessem ao juiz que o professor estivera na fazenda no dia da morte.

O professor antes de partir para São Tomé e Príncipe para onde seria deportado foi visitado por Daniela, o encontro do casal foi tão intenso e emocionante, que os dois ficaram cinco minutos, sem trocar uma única palavra, somente abraçados. Ignoravam as grades de ferro que os separavam. Daniela nunca mais viu o professor, a sua esperança acabava ali. A sua última tragédia seria a perda de seu amor, de sua única felicidade. Enlouquecida visitava todos os anos o cais da última despedida para tentar ver o rosto de seu homem até que um dia, atirouse ao mar e morreu.

Em A Última Tragédia, o autor nos convida a partilhar não só da força e da qualidade de sua veia prosaica, mas também da sensibilidade do olhar crítico com os quais observa a história de seu país tecendo o relato de sua nação. A literatura nacional é um dos mais expressivos documentos neste contexto que busca a reflexão em torno da história, da memória, da identidade e dos traumas, pois é capaz de revelar o que a história "oficial" silenciou, questionando "as verdades" construídas, atualizando e (re)definindo o discurso.

Preservar a memória e materializar o passado tem estado presente nas discussões dos estudos culturais e pós-coloniais, principalmente neste século. A fragmentação do mundo pósmoderno, traz o constante medo de esquecer o passado e, consequentemente, as identidades que nos compõem. Assim, surge a necessidade de compartilhar vivências através de narrativas que dão espaço para discursos e vozes sufocados pelos interesses ideológicos da ocidentalização, do monopólio imperialista e neocolonialista. Ao seguir o fluxo desse rio, deparamo-nos com o romance do guineense Abduali Sila (2002), um autor que se reinventa e tece na escrita artística elementos da política, rastros da história e fragmentos de uma nação pós-colonial.

A literatura de Abdulai Sila abre caminhos para viagens transculturais, desterritorializantes, marcadas pela utopia e distopia de um país forjado no trauma que ainda luta pela independência e por igualdade, mas, no contra fluxo de interesses, mergulha em uma longa guerra civil, responsável por milhares de mortos e por uma nação desencantada com o futuro. Nesse contexto, encontramos o escritor que africaniza a língua portuguesa, permeandoa de "Brincriações/provocriações" e vocábulos que revelam uma Guiné-Bissau híbrida, de embates entre o tradicional e o moderno.

$\mathrm{O}$ autor faz uma crítica incisiva ao presente que insiste em excluir, violentar, subalternizar os povos pós-coloniais. Mediante um fingimento prosaico, o escritor sai em busca de um entrelugar, encontrando refúgio em uma tessitura da memória a qual retrata a corrosão das guerras coloniais na Guiné-Bissau. No entanto, esse trajeto segue um caminho errante, assim como a própria Ndani em A Ultima Tragédia que alegoricamente representa a nação forjada no contato com o colonizador, estilhaçada pelos traumas, mas que mesmo assim segue adiante agarrandose a um último fio de esperança em uma vida de desventuras.

A personagem procura fugir dos locais culturais que a aprisiona, no entanto, isso nem sempre acontece e, quando se realiza, é de forma traumática. Nesse sentido, Ndani/Daniela aparece como um sujeito duplamente colonizado, pela herança cultural e pela sociedade "moderna". Ainda que o autor realize uma crítica a essa situação, percebemos que a personagem 
não avança socialmente e acaba repetindo histórias opressoras do passado, criando um determinismo na construção do feminino, pois essas tensões não são problematizadas. Desse modo, o escritor se apropria do espaço ficcional para ponderar as relações entre a escrita e o contar estórias que, embora marcadas pelo sofrimento, reiteram a importância do sonhar.

Abdulai Sila se posiciona em um lugar social e, com isso, cria a expressão de uma coletividade. As personagens coloniais ganham voz através do romance, permitindo-nos encontrar na obra respostas para questionamentos do tipo: “quem realmente somos?". O que para Kwame Anthony Appiah (1997), tem uma profícua significação política. Escrever para e sobre nós mesmos, portanto, ajuda a constituir a moderna comunidade da nação. Desvendando processos e esclarecendo as reais condições vivificadas na atualidade. Outro aspecto que também nos permite entender as identidades fragmentadas pelo processo colonial é a ação de desterritorialização que o autor estabelece na obra.

Homi Bhabha (1998), ao escrever sobre a nação, argumenta de que forma o processo de exclusão/inclusão ou de desterritorialização indica a necessidade de um tempo duplo para a narração da nação, baseado no conceito de disseminação, espalhamento e concentração de identidades onde estas identidades assumem um caráter relacional. A posição do colonizado e do colonizador tange na desterritorialização do eu e do Outro, isto é, ambos introjetam os costumes e a cultura do outro partindo de mundos particulares para adentrarem no lócus diferente, ao sentirem que foram desterritorializados. Afinal, surge aí uma espécie de terceiro ser pelo processo de hibridismo cultural não mais sendo como o inicial (BHABHA, 1998).

A desterritorialização na obra apresenta-se também, na apropriação da língua portuguesa onde a narração busca recuperar o discurso traumático das vítimas do colonialismo, através de um discurso literário polifônico, em que há a apropriação das estruturas combinadas com a grande capacidade efabulativa silariana. O resultado é uma literatura, em língua portuguesa, fecundada pela riqueza da seiva das línguas bantu e crioulo. Esse fluir entre tradição, língua e culturas numa busca de expressão de uma ideia de nação aproxima-se da visão de Bhabha (1998) em um momento ulterior acerca da diferença como reflexo de traços culturais ou étnicos preestabelecidos, "A Articulação social da diferença, na perspectiva da minoria, é uma negociação complexa, em andamento, que procura conferir autoridade aos hibridismos culturais que emergem em momentos de transformação histórica" (BHABHA, 1998, p. 20).

Nem por isso a temática principal de $A$ Última Tragédia deixa de ser engajada, no sentido da teoria pós-colonial: trata-se da exploração do homem negro africano e da riqueza de seu território. O régulo, conduzido pela necessidade de expiar seu trauma e tomado pelo sentimento de coletividade, encontra através do relato em forma de testamento uma maneira de retramar os fatos supertramados de sua narrativa existencial, a fim de forjar um alívio catártico de sua consciência coletiva fendida pela história devotava àqueles que, como ele, eram vítimas da opressão do poder colonizador.

Todas as protagonistas se movimentam em torno do Eu com o meio em uma possibilidade de ajustes que os combinem harmonicamente. Com o professor não seria diferente, este jamais será o mesmo; da educação advinda da catequese com os missionários que lhes ensinaram a 
língua e a cultura do colonizador, torna-se um homem plural, marcado pela dupla inscrição cultural, ambivalente, pós-colonial com sua força parcial e dupla:

Essa força e mais do que o mimético e menos do que o simbólico; é ela que perturba a visibilidade da presença colonial e torna problemático o reconhecimento de sua autoridade. Para serem autorizadas, suas regras de reconhecimento devem refletir, a saber, sua opinião consensual; para serem poderosas, estas regras de reconhecimento devem ser atingidas de modo a representar os objetos exorbitantes da discriminação que estão além de seu alcance (BHABHA, 1998, p. 162).

Esse processo de articulação é um processo dinâmico, como dito, de permanente troca, que se dá na tentativa de essas minorias encontrarem uma identidade própria, constituída por esses hibridismos e distante dos polos fixos tradicionais. Em Sila (2002), esse movimento se caracteriza justamente por permitir que as personalidades e sua cultura nativa ganhem voz para expressar a consciência nacional que, incerta ou oprimida, passa pela literatura. $\mathrm{O}$ lar e sua construção na língua, portanto, é um dos meios mais cruciais para lembrar (e assim juntar) os fragmentos de uma cultura/história/identidade violentada entre os muitos ditos e não-ditos de diversos discursos. O papel de Daniela e do Professor na obra, tornam-se comuns à condição do sujeito guineense que, de um modo geral, submetia-se à lei da assimilação a fím de ser oficialmente reconhecido como civilizado.

Os indivíduos em Sila (2002) não são o início nem o fím da narrativa nacional; representam a fronteira divisória entre os poderes totalizantes do social e as forças que significam os discursos mais específicos a favor do conflitual, dos interesses desiguais e das identidades diferenciadas dentro da população. Essa escrita se configura como um relato de nação porque registra a história atualizada da Guiné-Bissau, a partir da apresentação de eventos, figuras, situações, lugares, vivências afetivas e processos históricos. A voz percorre os movimentos temporais, refletindo sobre o passado cultural e histórico, analisando criticamente o presente e projetando um futuro diferente para a nação guineense.

\section{Referências}

APPIAH, Kwame Anthony. Na casa de meu pai. Rio de Janeiro: Contraponto, 1997.

AUGEL, Moema Parente. A nova literatura da Guiné-Bissau. Bissau: INEP, 1998.

AUGEL, Moema Parente. $O$ desafio do escombro: a literatura guineense e a narração da nação. 2005. 387 f. Tese (Doutorado em Literatura Portuguesa) - Faculdade de Letras, Universidade Federal de Rio de Janeiro, Rio de Janeiro, 2005.

AUGEL, Moema Parente. O discurso literário dos anos noventa: revelando os arquivos do silêncio. In: AUGEL, Moema Parente. O desafio do escombro: nação, identidades e póscolonialismo na literatura da Guiné-Bissau. Rio de Janeiro: Garamond, 2009, p. 290-309.

BENJAMIN, Walter. Teses sobre filosofia da história. In: KOTHE, Flávio R. (Org.). Sociologia. São Paulo: Ática, 1985. p. 153-164. 
BHABHA, Homi. Narration and narration. London: Rouledge, 1990.

BHABHA, Homi K. O local da cultura. Trad. de Myriam Ávila, Eliana Lourenço de Lima Reis, Gláucia Renate Gonçalves. Belo Horizonte: Ed. UFMG, 1998.

CHEVAlIER, Jean; GHEERBRANT, Alain. Dicionário de Símbolos: mitos, sonhos, costumes, gestos, figuras, cores, números. Trad. de Vera da Costa e Silva [et al]. 23. ed. Rio de Janeiro: José Olympio 2009.

FANON, Frantz. Pele negra, máscaras brancas. Trad. de Renato da Silveira. Salvador: EDUFBA, 2008.

FANON, Frantz. Os condenados da terra. Juiz de Fora: Editora UFJF, 2010.

SILA, Abdulai. A Última Tragédia. In: SILA, Abdulai. Mistida (Trilogia). Praia: Instituto Camões, 2002, p. 17-169.

WHITE, Hayden. Trópicos do discurso: ensaios sobre a crítica da cultura. Trad. de Alípio Correia de Franca Neto. São Paulo: Ed. da Universidade de São Paulo, 1994.

VALANDRO, Letícia. A difícil Mistida guineense nação e identidade da Guiné-Bissau através da trilogia de Abdulai Sila. 2011. 133 f. Dissertação (Mestrado em Literaturas Portuguesas e Luso-Africanas) - Instituto de Letras, Universidade Federal do Rio Grande do Sul, Porto Alegre, 2011.

\section{NOTAS DE AUTORIA}

Jonh Jefferson do Nascimento Alves (johnjeffersonn@gmail.com) é doutorando em Letras pelo Programa de Pós-Graduação em Linguística e Literatura da Universidade Federal de Alagoas - UFAL. Mestre em Letras pela Universidade do Estado do Rio Grande do Norte UERN. Possui especialização em Língua Portuguesa, Linguística e Literatura, pela Faculdade Aldemar Rosado - FAR e graduação em Letras, Língua Portuguesa e respectivas Literaturas pela Universidade Estadual do Maranhão - UEMA.

\section{Como citar esse artigo de acordo com as normas da revista}

ALVES, Jonh Jefferson do Nascimento. Os (d)anos da colonização, as identidades póscoloniais e a busca da guinendade em A Última Tragédia de Abdulai Sila. Anuário de Literatura, Florianópolis, v. 25, n. 2, p. 172-186, 2020.

\section{Contribuição de autoria}

Não se aplica.

\section{Financiamento}

Não se aplica.

\section{Consentimento de uso de imagem}

Não se aplica.

Aprovação de comitê de ética em pesquisa

Não se aplica. 


\section{Licença de uso}

Este artigo está licenciado sob a Licença Creative Commons CC-BY. Com essa licença você pode compartilhar, adaptar, criar para qualquer fim, desde que atribua a autoria da obra.

\section{Histórico}

Recebido em: 19/03/2020

Revisões requeridas em: 25/05/2020

Aprovado em: 14/08/2020 